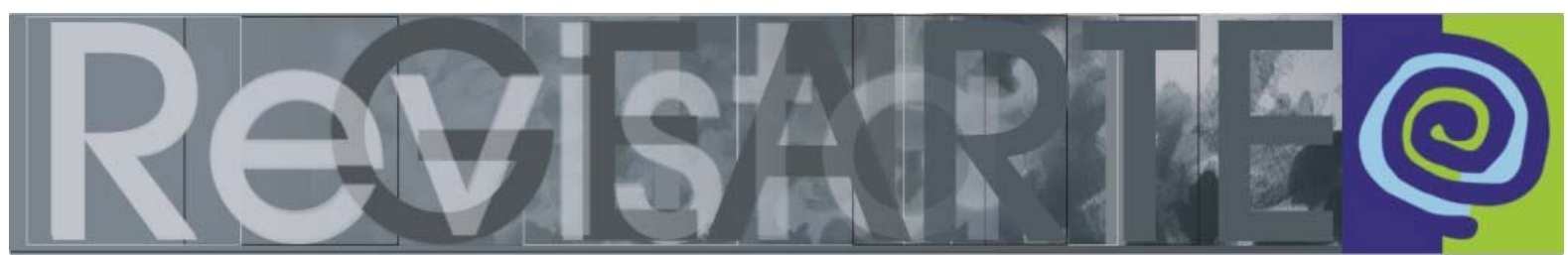

ISSN 2357-9854

\title{
Ensaio Visual: Escolinha de Arte de São Paulo em três capítulos Primeiro Capítulo: Sequencialidade ${ }^{1}$
}

\author{
Ana Mae Barbosa (USP e UAM - Brasil) \\ Sidiney Peterson Ferreira de Lima (Pesquisador independente - Brasil)
}

\begin{abstract}
RESUMO
Neste ensaio visual, apresentamos a Escolinha de Arte de São Paulo, uma experiência no campo de ensino da Arte que durou pouco, de março de 1968 a junho de 1971. Foi um laboratório de pesquisa para as teorias da época e de práticas antecipatórias como a ideia de ensinar todas as Artes, através de um só professor e de interdisciplinarizar as Artes ensinadas por diferentes professores especializados reunidos em torno de uma situação-problema comum a todos. Éramos contra a separação entre conteúdo e forma, por isso não dávamos temas, mas provocávamos situações problematizadoras. A observação direta de cada criança nos levava a estudar a sequencialidade de sua construção gráfica. Os estudantes eram orientados no sentido da busca da forma adequada para a ideia. O julgamento era feito por eles próprios. Portanto, persistir tentando era um hábito assim como a experimentação com diferentes materiais associados a jogo de luz com lanternas e a construção gráfica de equivalentes configuracionais aos resultados obtidos. Frequentes associações cognitivas e visuais, da Arte com o Design e da Arte com imagens de outras mídias, eram feitas através de diálogos críticos e questionadores não só gráficos e plásticos, mas verbais também. Aqui apresentamos o primeiro de três capítulos pelos quais daremos a conhecer essa experiência de 45 anos atrás.
\end{abstract}

PALAVRAS-CHAVE

História. Escolinhas de Arte. Ideação e Construção.

\begin{abstract}
In this visual essay, we present the Little School of Art of São Paulo, an experience in art education that was short-lived, from March 1968 to June 1971. It was a research laboratory for theories of the time and practices such as the idea to teach all the arts, through one teacher and, interdisciplinarizar the Arts taught by different specialized teachers gathered around a common problem situation. We were against the separation between content and form so we did not give themes but we used to provoke problem-solving situations. Direct observation of each child led us to study the sequence in terms of its graphic construction. We oriented students towards the search for appropriated form for the idea. Therefore, to persist trying was a habit as well as experimentation with different materials associated with the play of light with lanterns and graphic construction of configurational equivalent to the results obtained. Frequent cognitive and visual associations were made in Art and Design; Art and Images of other midia through critical questioning and dialogue not only graphics and plastics, but also verbal. Here we present the first of three chapters of this experience that happened 45 years ago.
\end{abstract}

\section{KEYWORDS}

History. Little School of Art. Ideation and Construction

\footnotetext{
${ }^{1}$ As imagens apresentadas neste ensaio pertencem ao acervo pessoal de Ana Mae Barbosa. BARBOSA, Ana Mae; LIMA, Sidiney Peterson Ferreira de. Ensaio Visual: Escolinha de Arte de São 230 Paulo em três capítulos Primeiro Capítulo: Sequencialidade. Revista GEARTE, Porto Alegre, v. 2, n. 2, p. 230-255, ago. 2015.

Disponível em: http://seer.ufrgs.br/gearte
} 


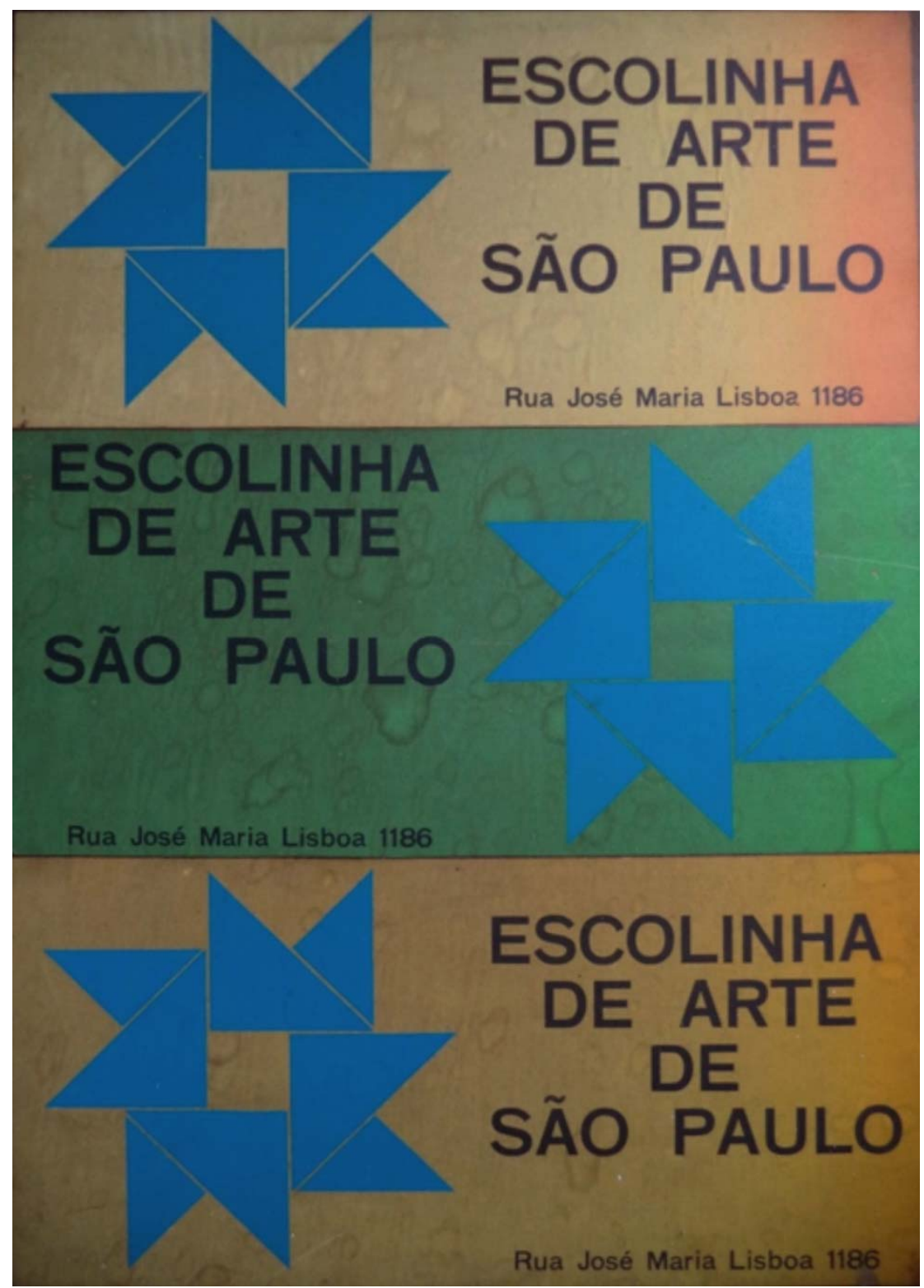

Placa da Escolinha de Arte de São Paulo, Diana Mindlin, 1968. 


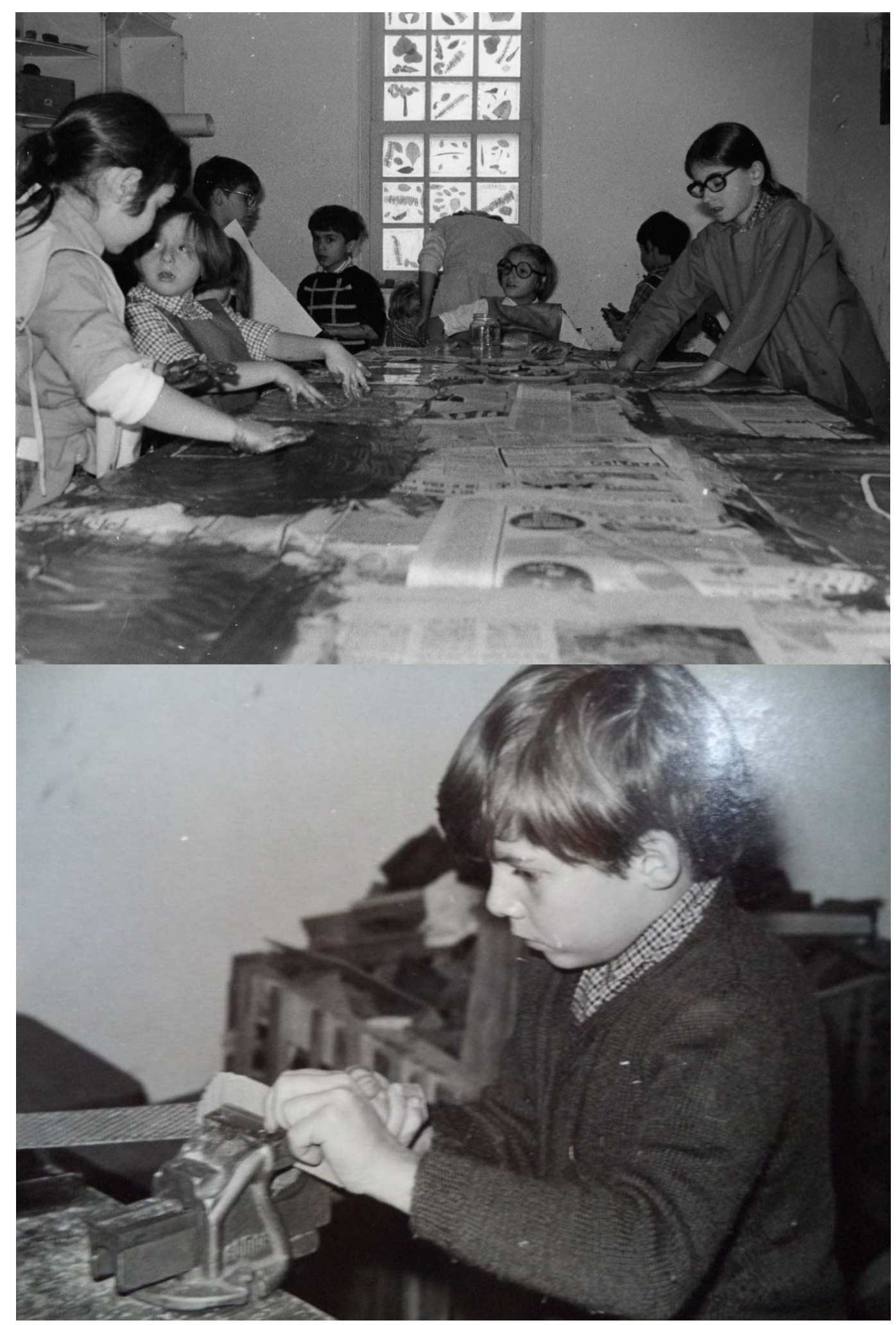



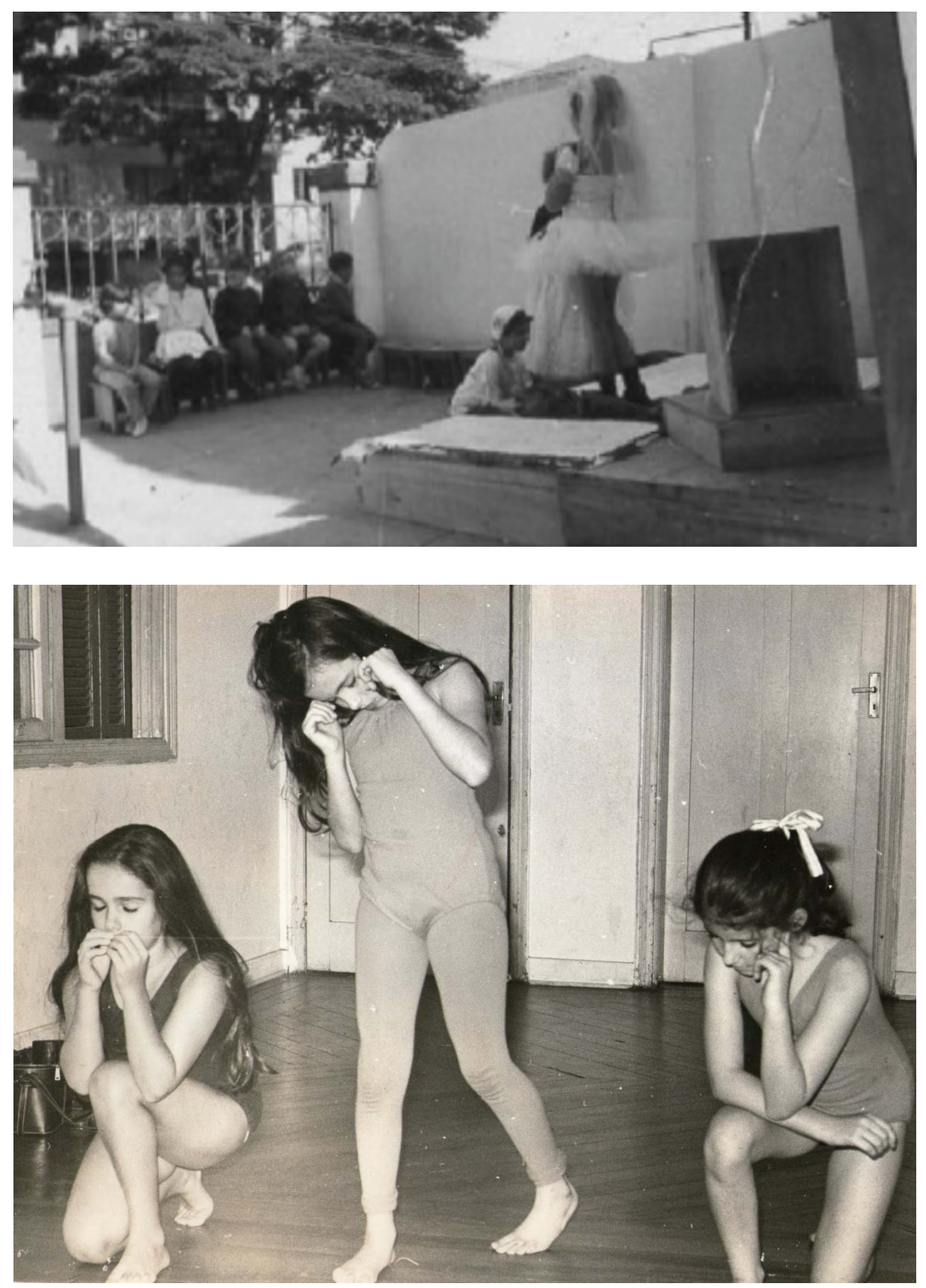


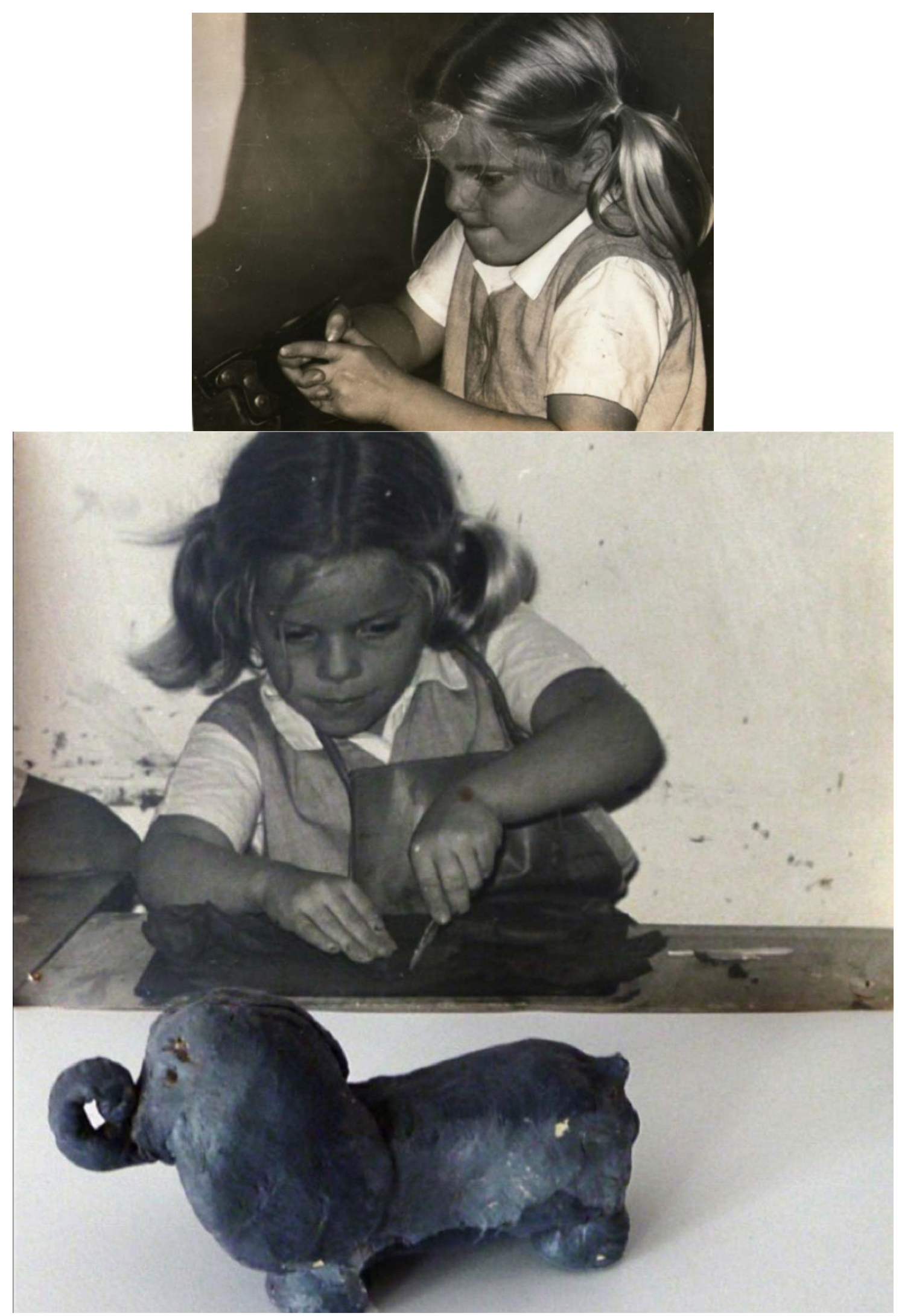

Fotos do Professor Roberto Guglielmo 
Garatujas de uma criança de quatro anos de idade, realizadas no primeiro dia de aula na EASP,. eEm sequência de produção.

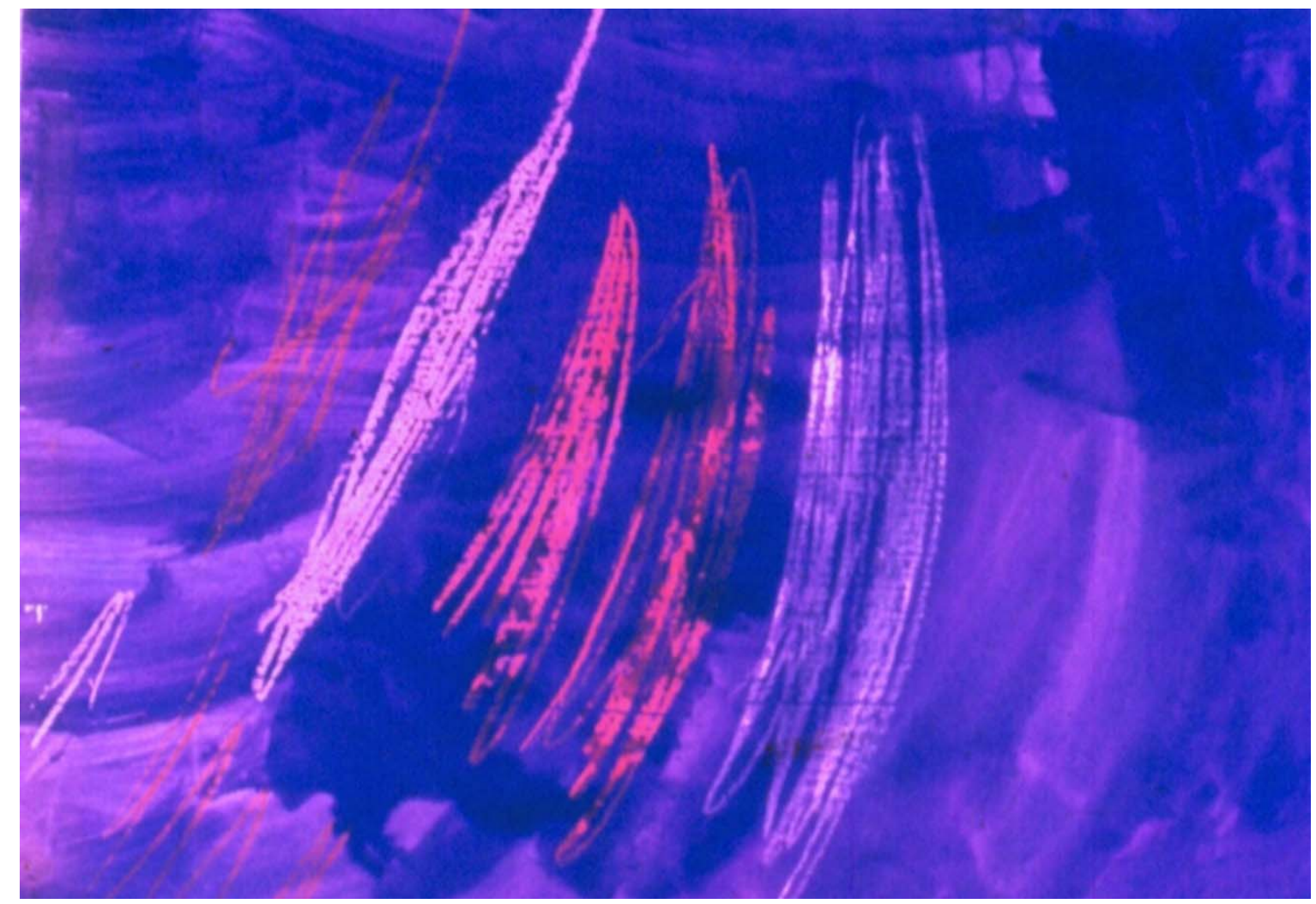

Garatuja longitudinal. 


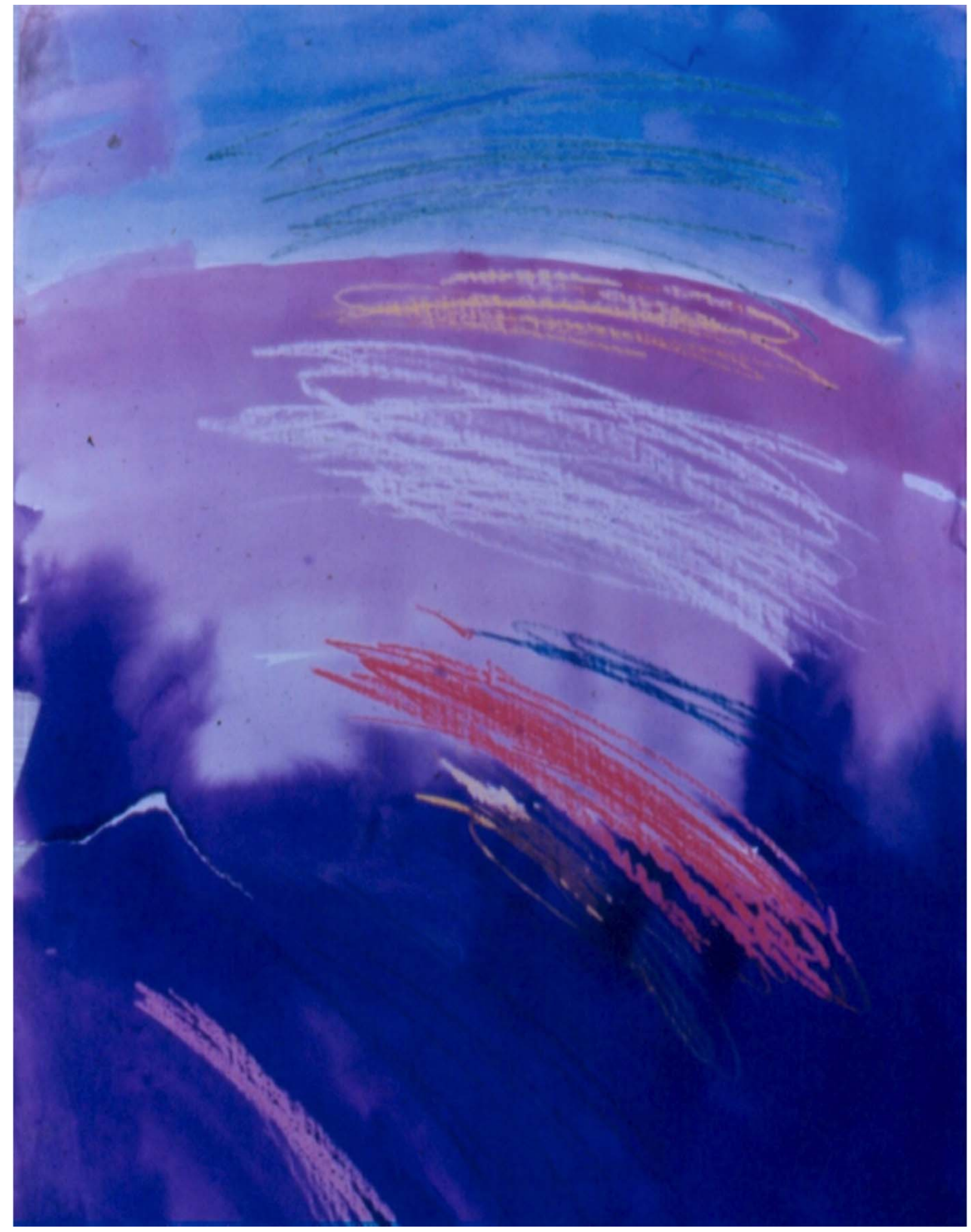

Garatuja: com movimentos da esquerda para a direita e da direita para a esquerda. 


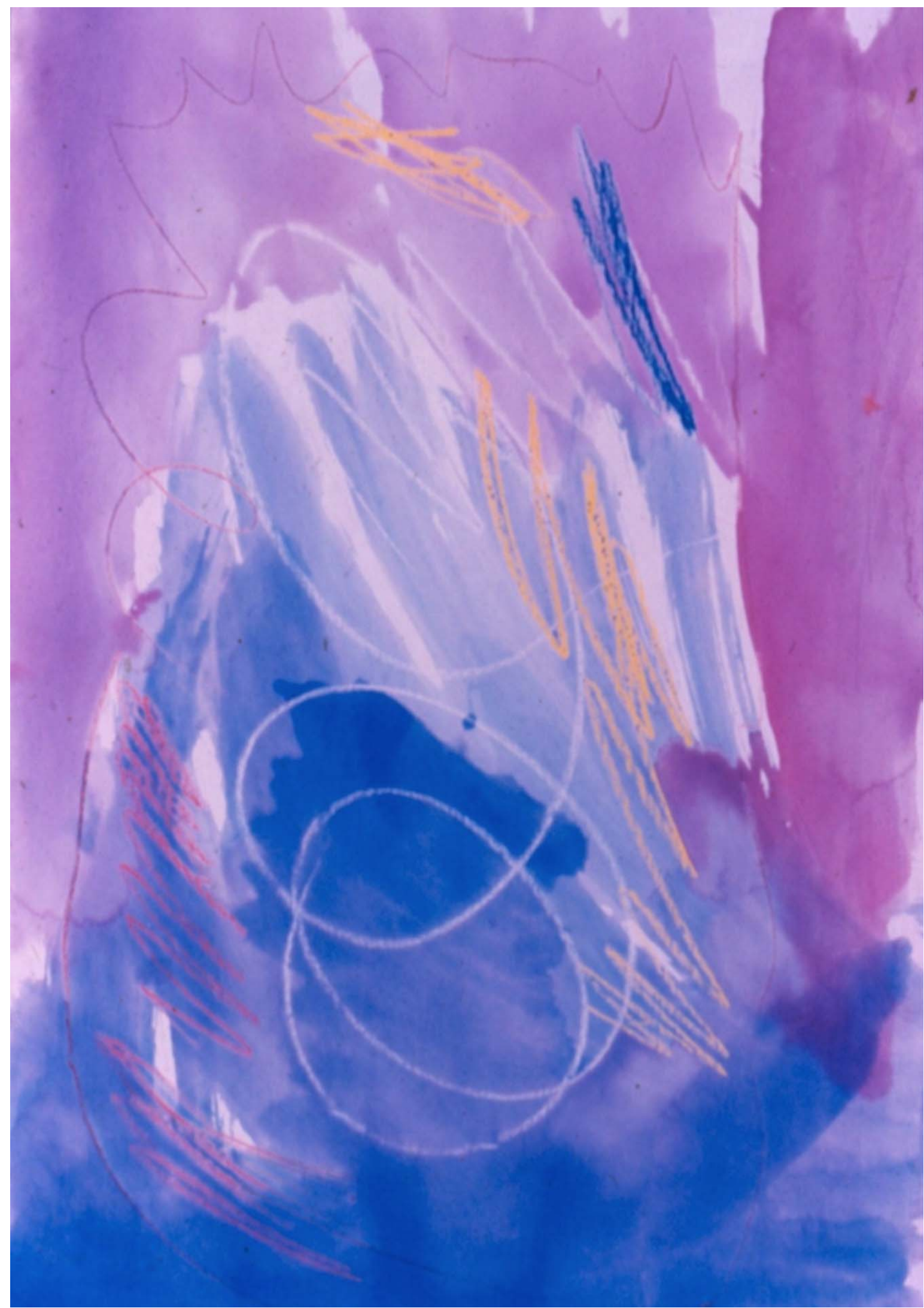

Combinação de garatuja circular com as categorias anteriores. 


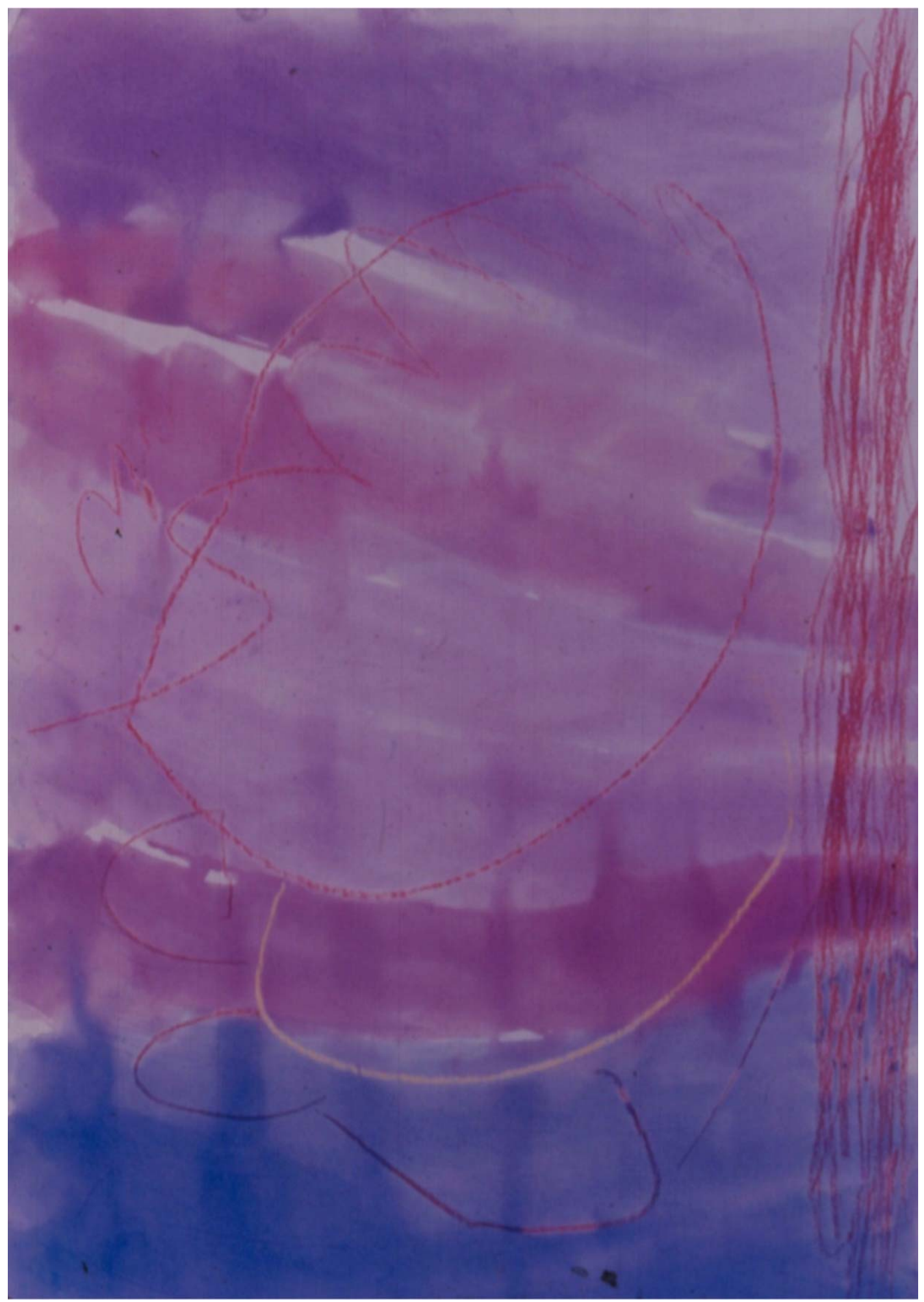

Garatuja em círculo fechado, primeira noção de coisidade (Rudolf Arnheim). 


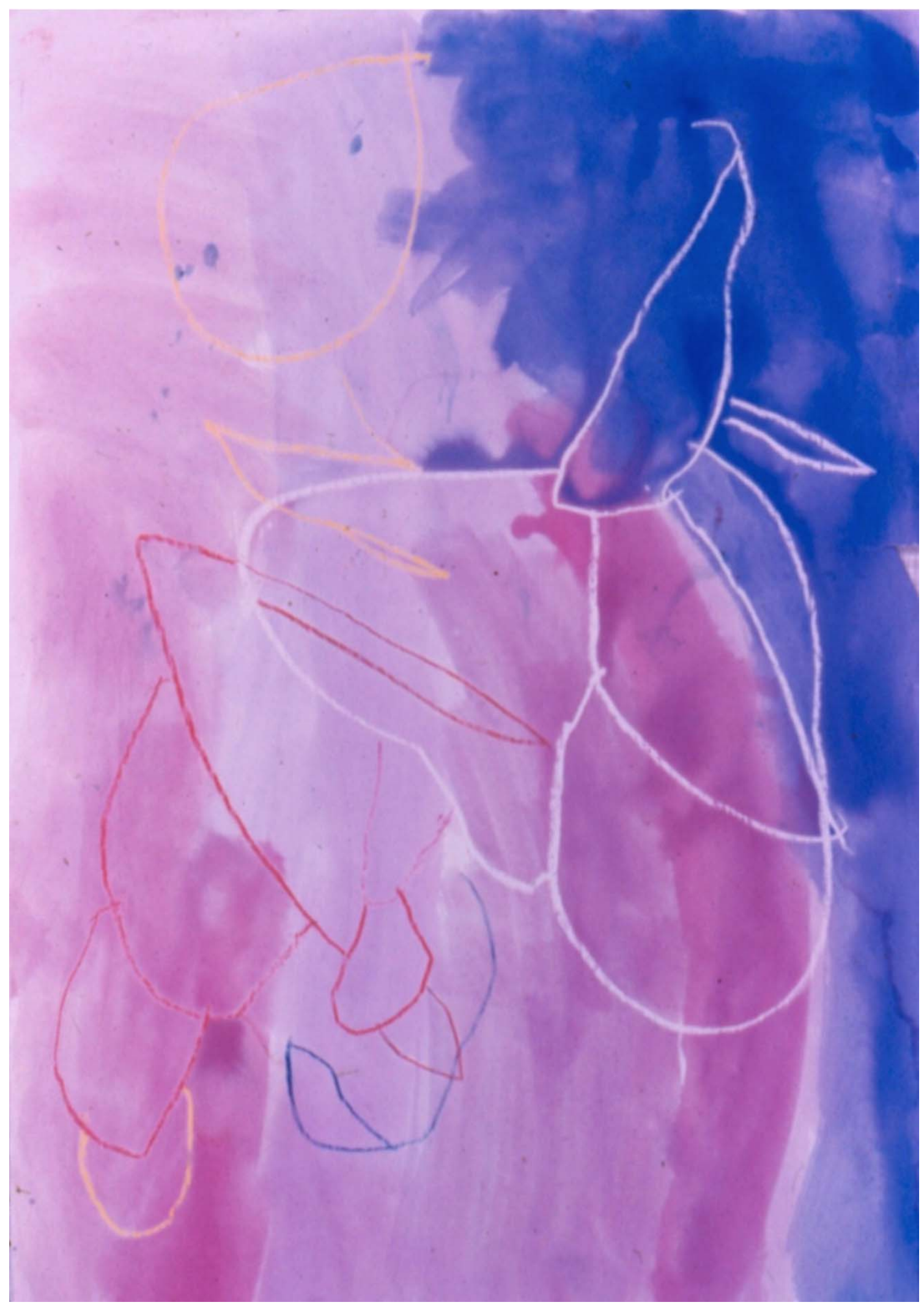

Primeiros padrões de diagrama (Rhoda Kellogg). 


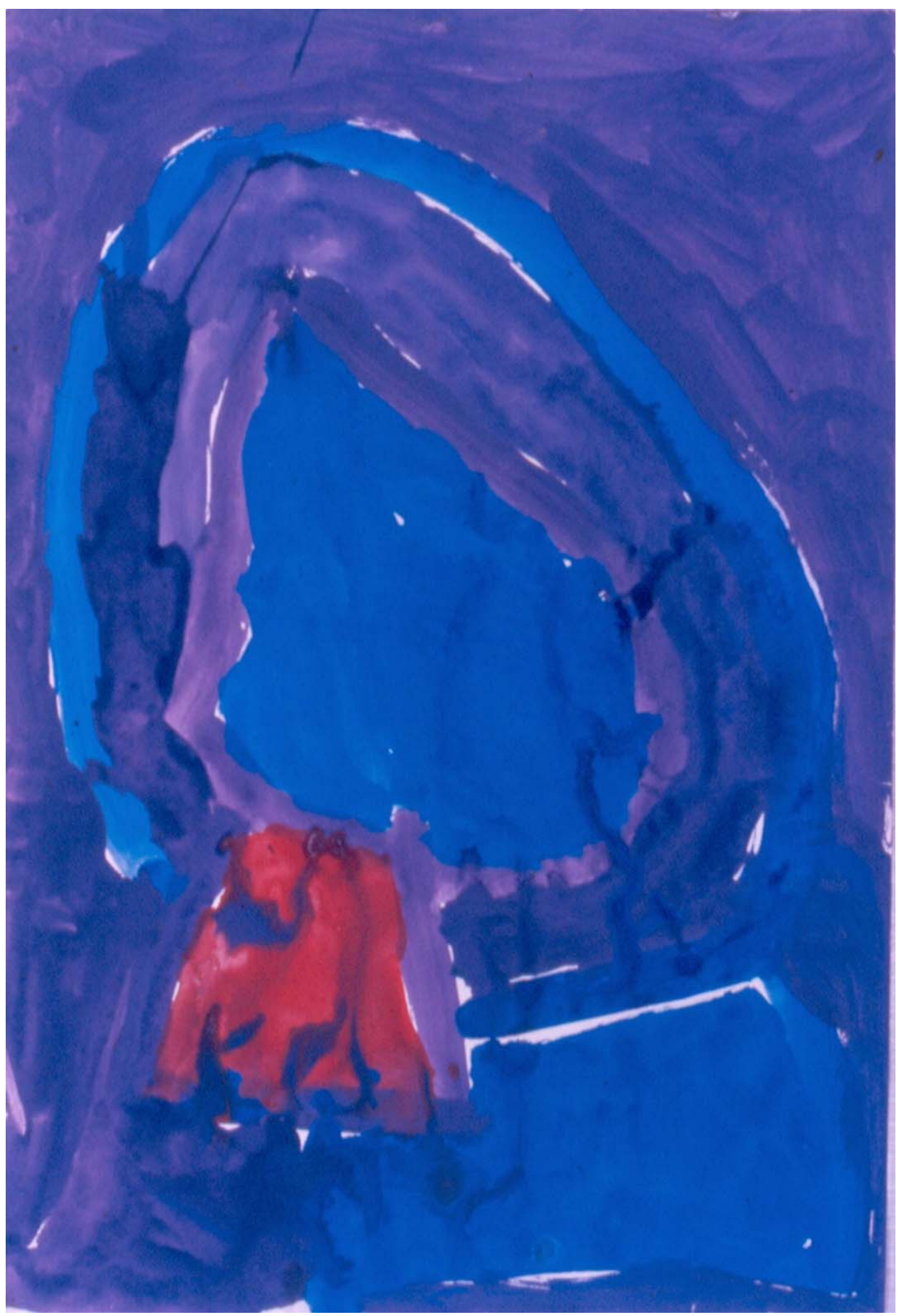

Início do pré-esquema (Viktor Lowenfeld). 


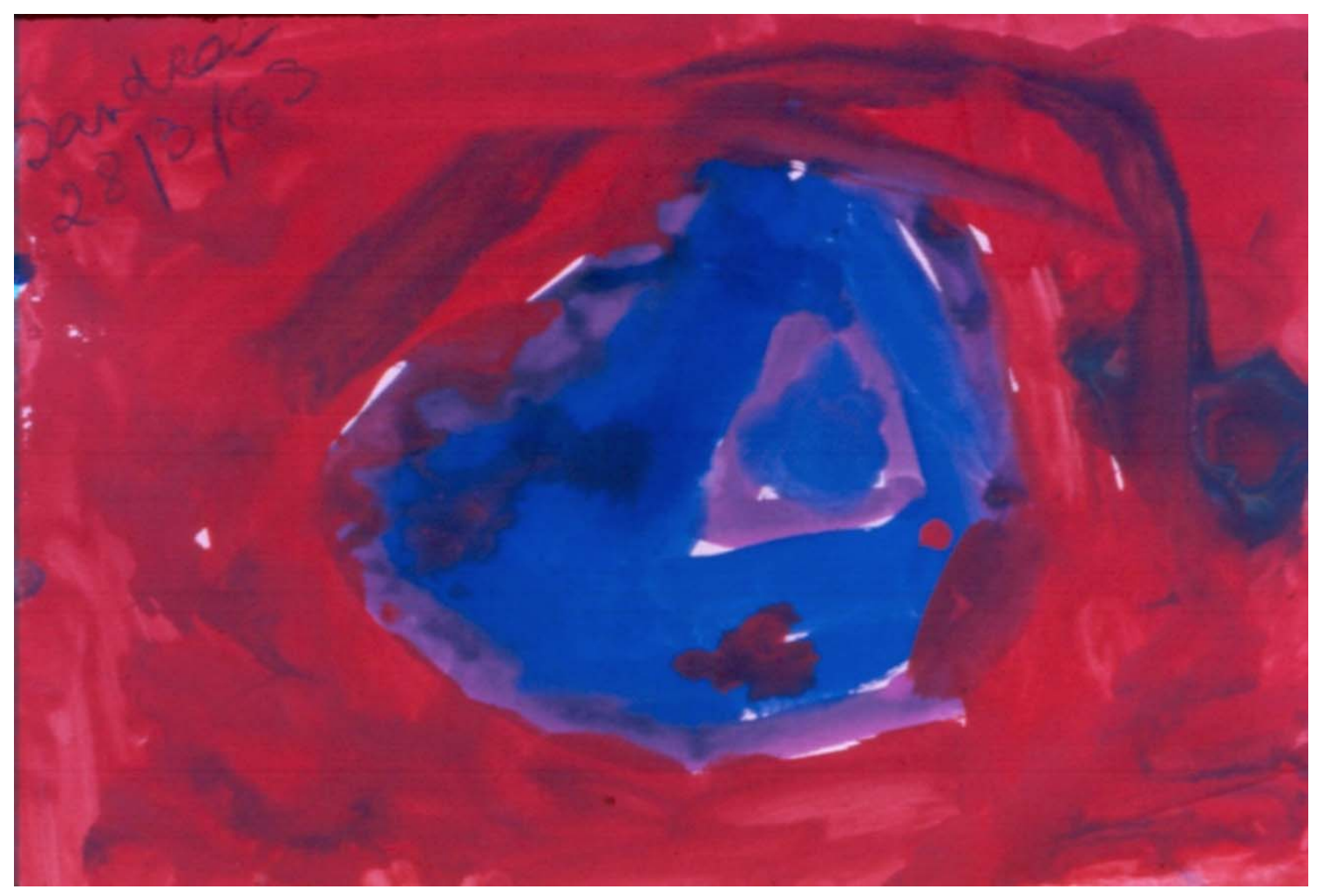

Início do pré-esquema (Viktor Lowenfeld). 
Processo de desenvolvimento da figura humana. Duração de um ano por uma menina de seis/sete anos de idade, aluna da EASP e atualmente artista visual e professora de desenho em São Paulo.

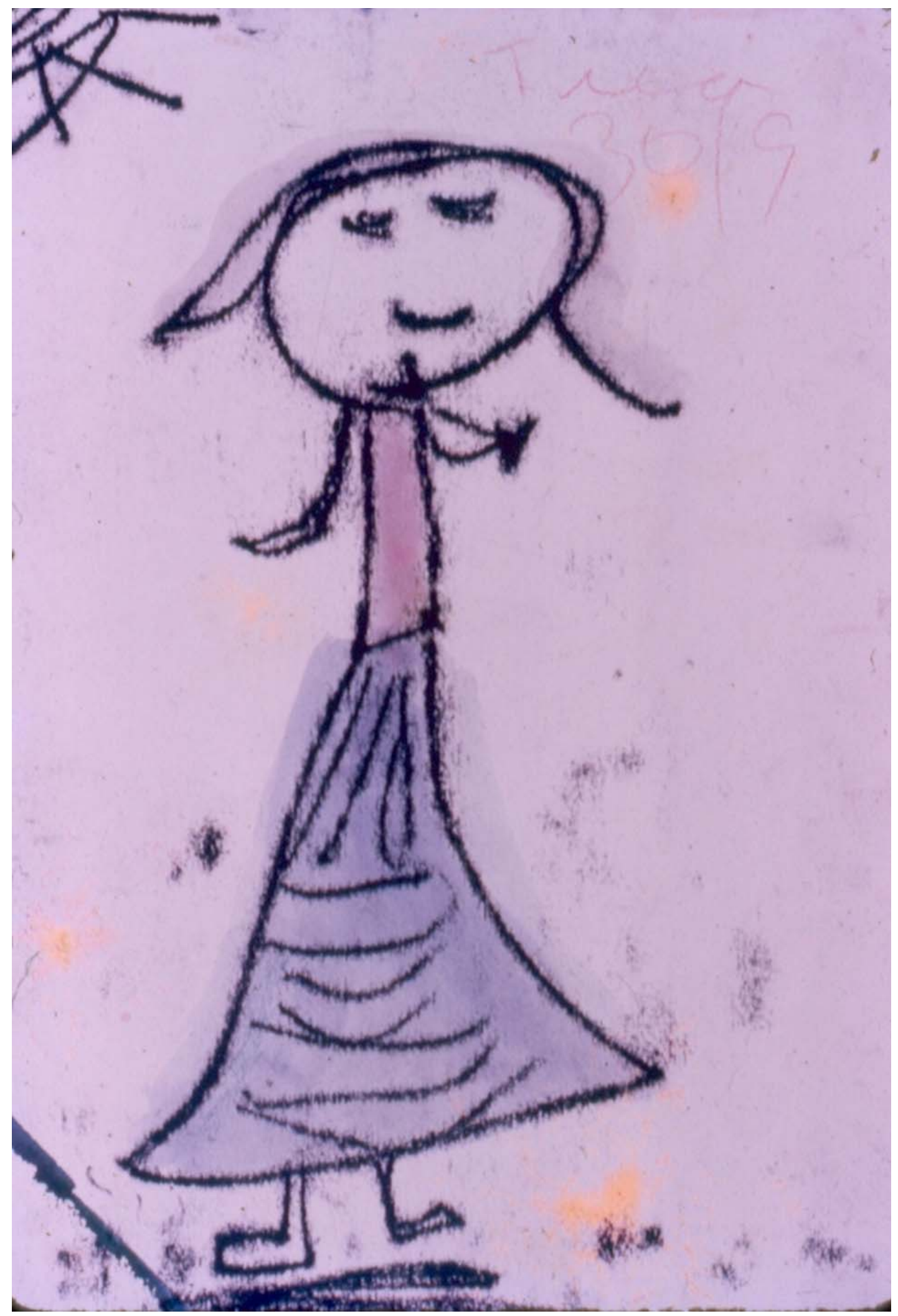




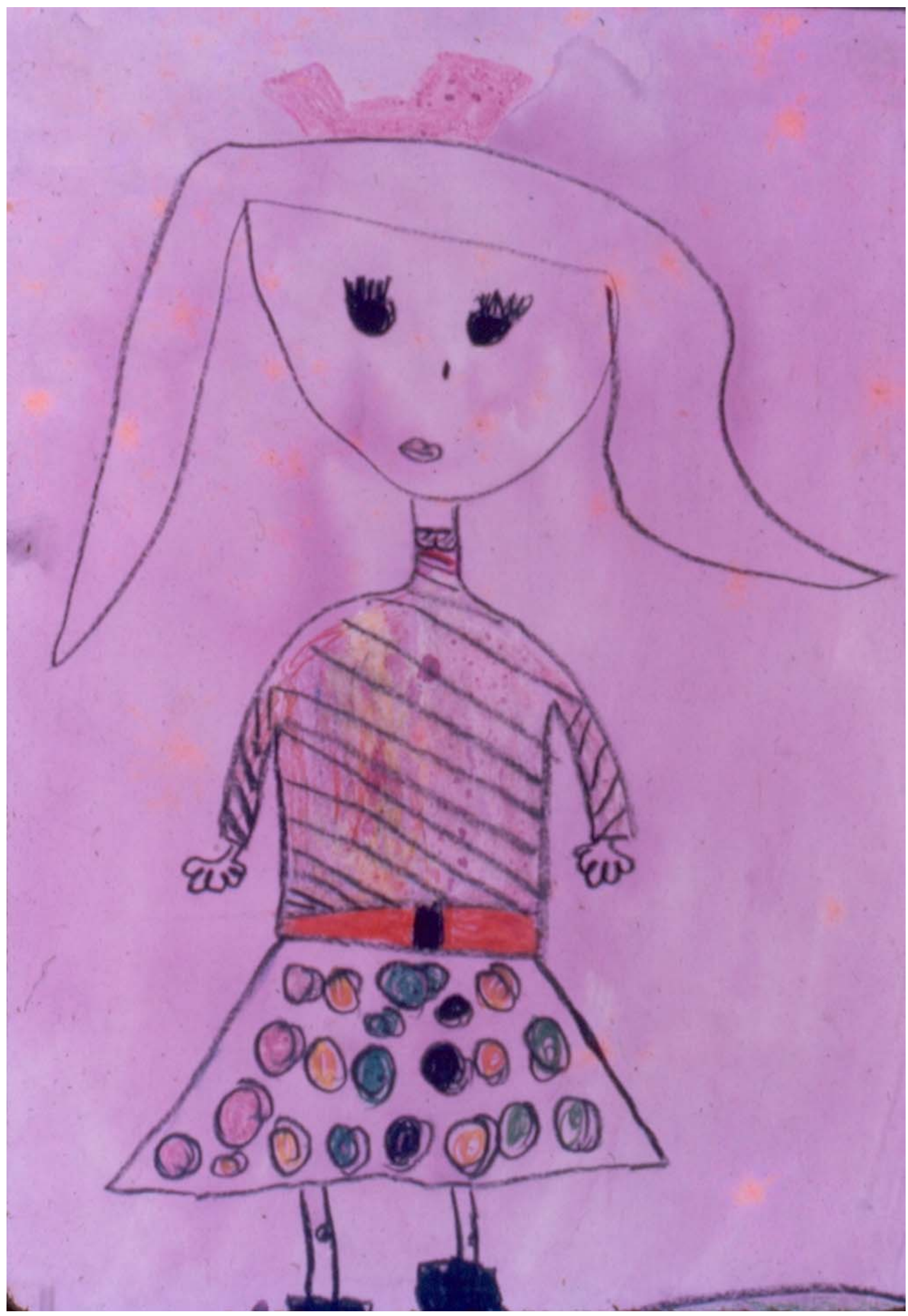




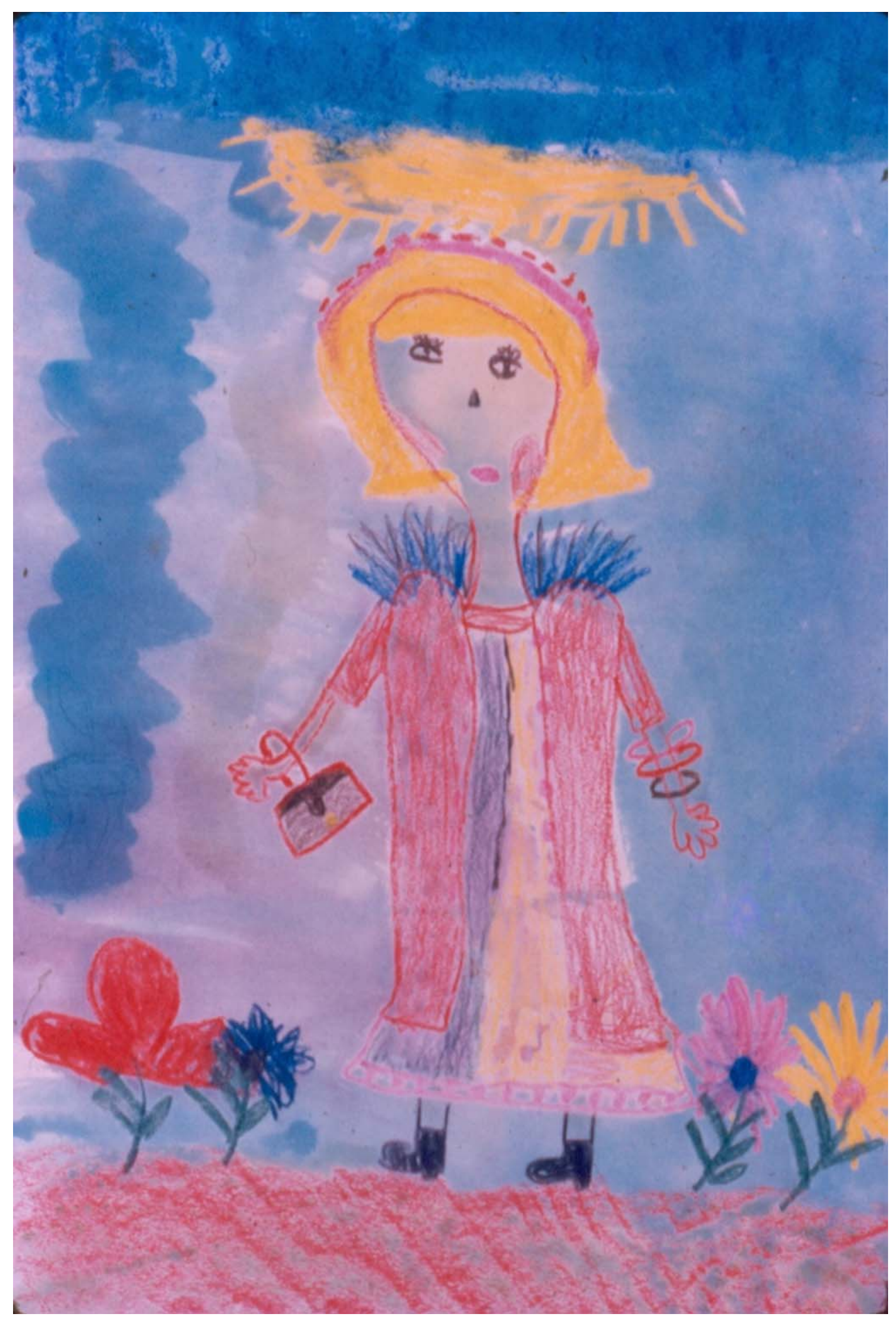




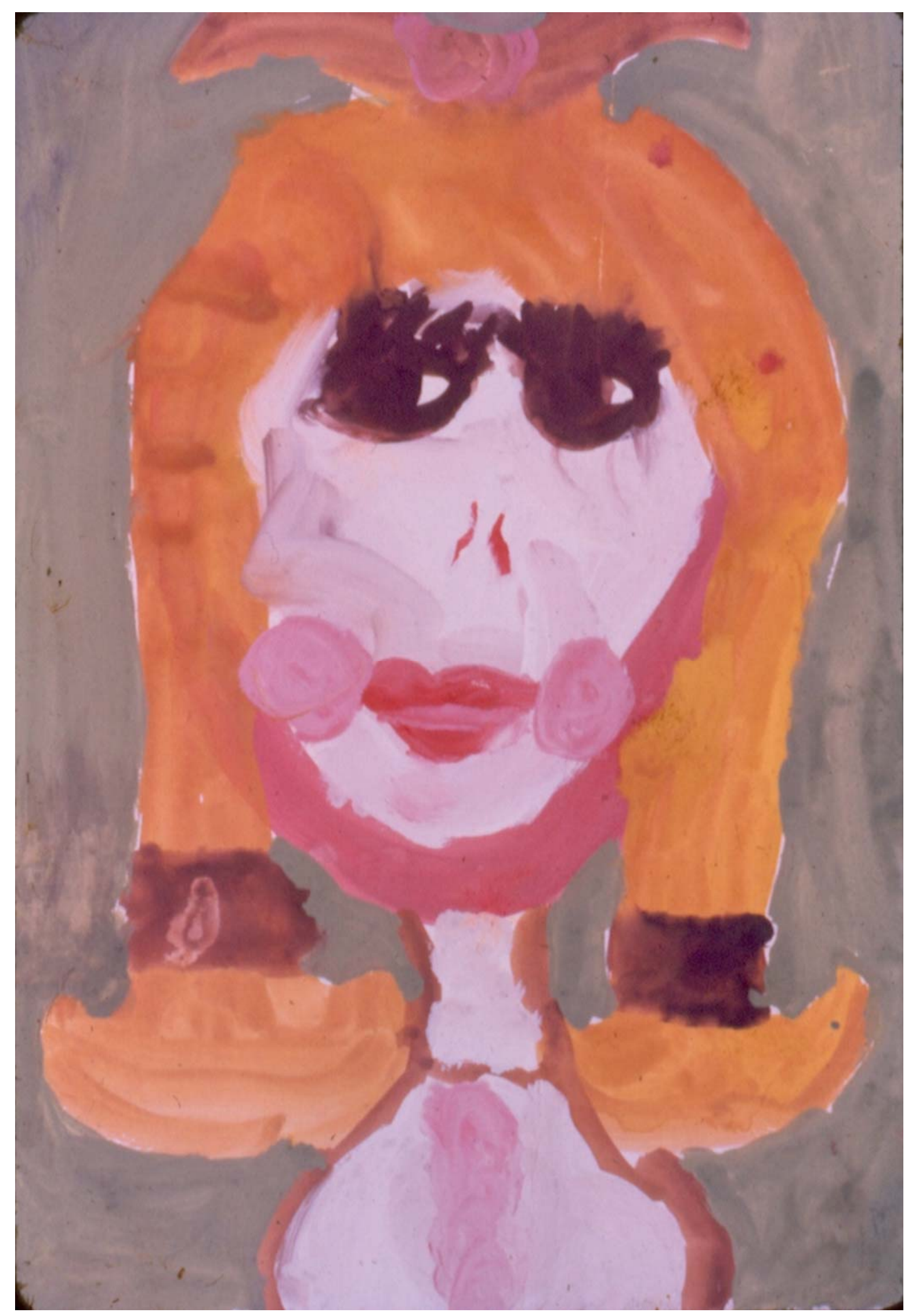




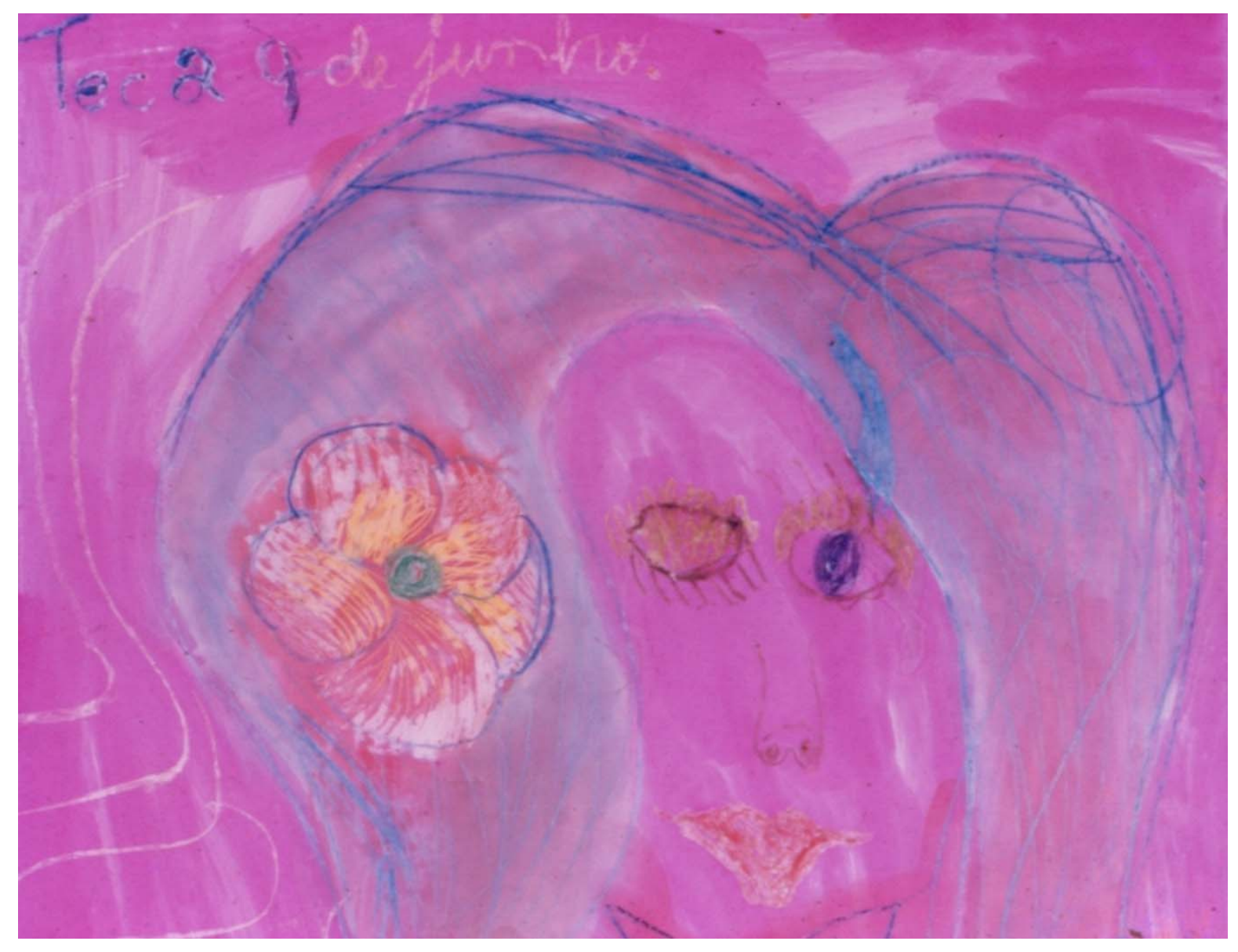


Pesquisa com materiais escolhidos por aluno da EASP. Papel celofane incolor, pedaços de papel celofane coloridos, palhas de embalagem e exploração das sombras com efeitos de luz provocados por uma lanterna.

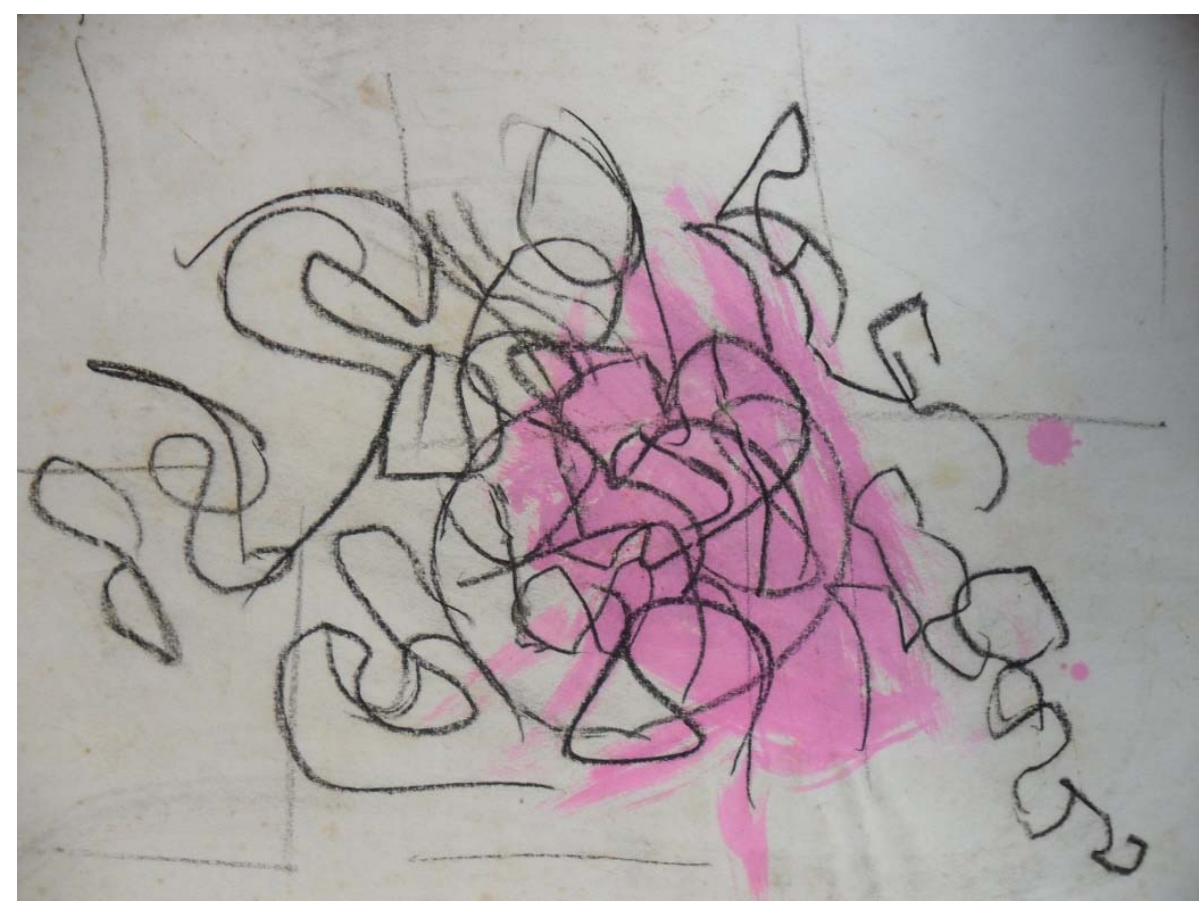

Primeira tentativa de representação gráfica da experiência. Desenho considerado inadequado, pela criança.

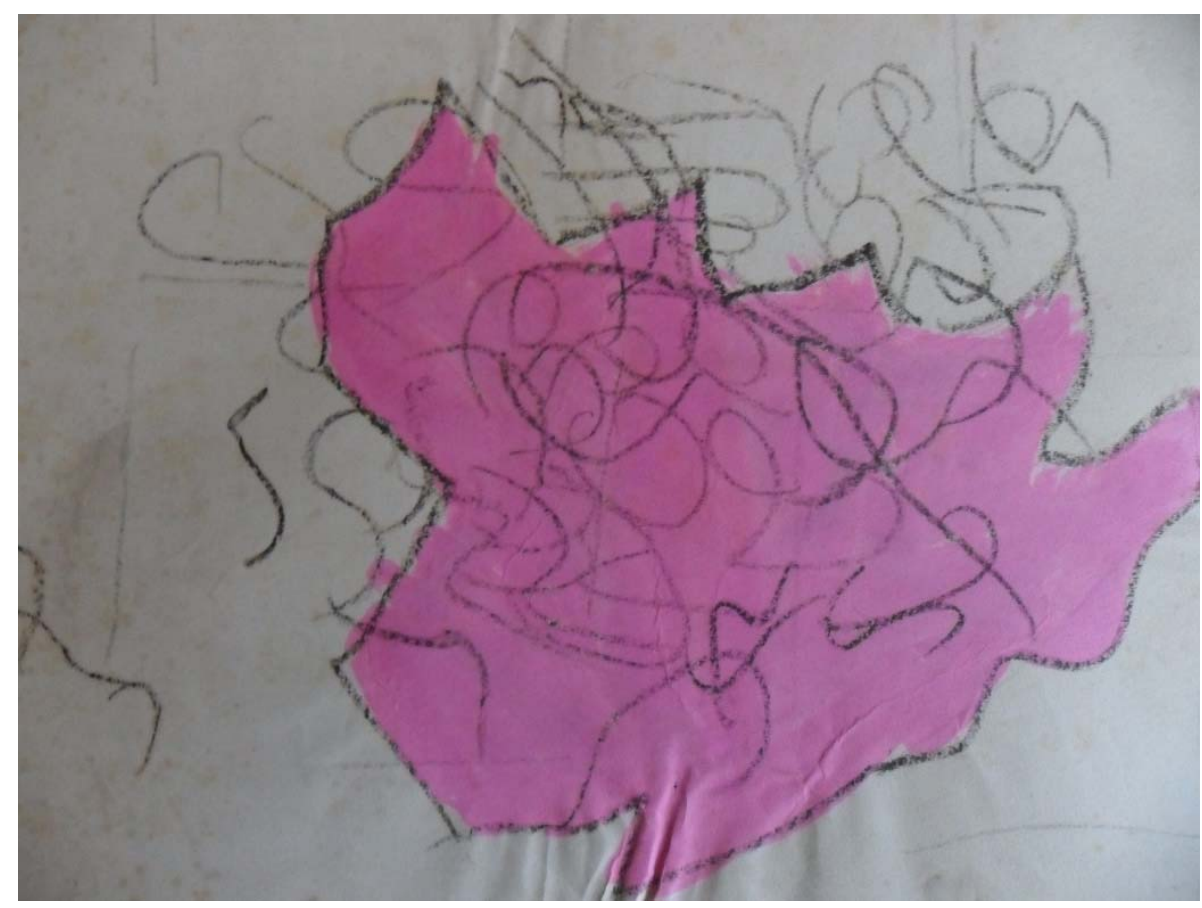

Segunda tentativa. Desenho também considerado inadequado pela criança, por estabelecer limites da cor muito marcados. 


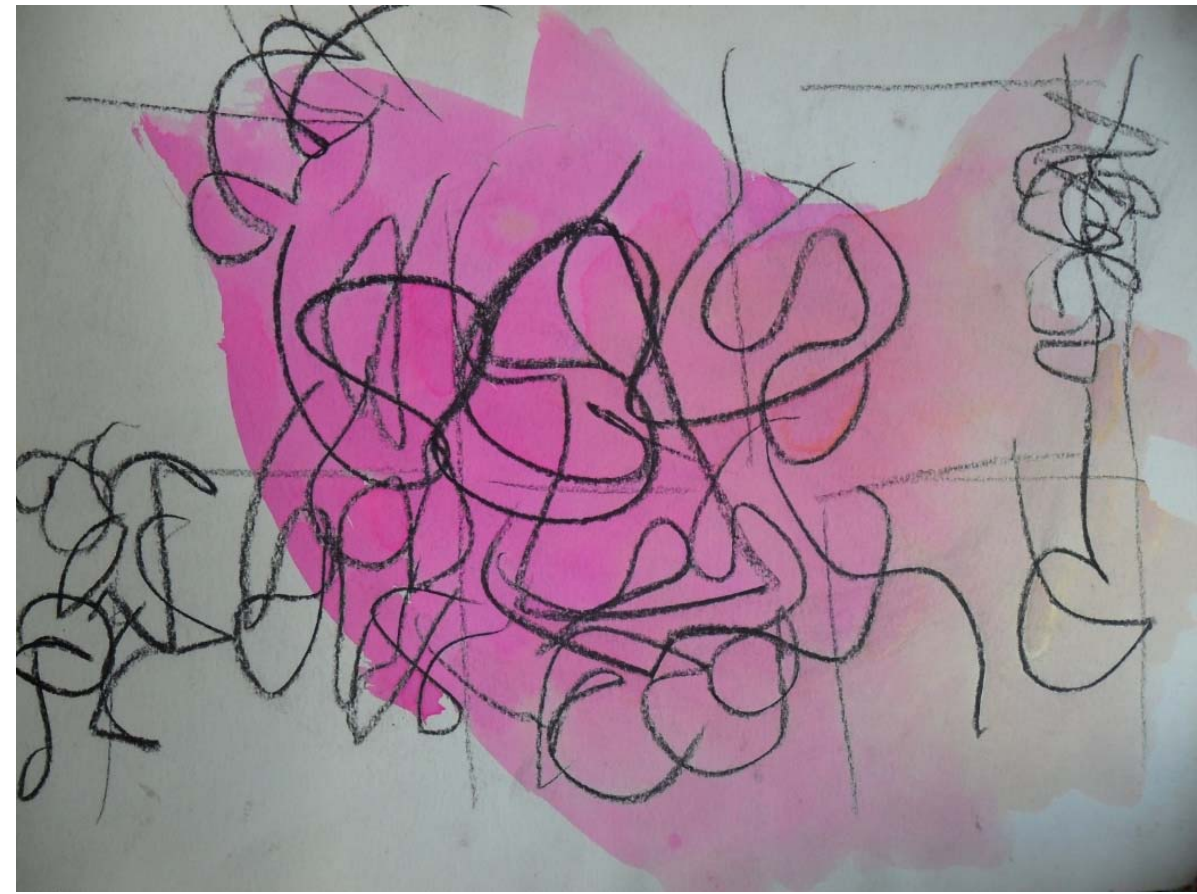

Representação gráfica considerada adequada pela criança. Proposta de aluna de onze anos da EASP: desenho que signifique expansão.

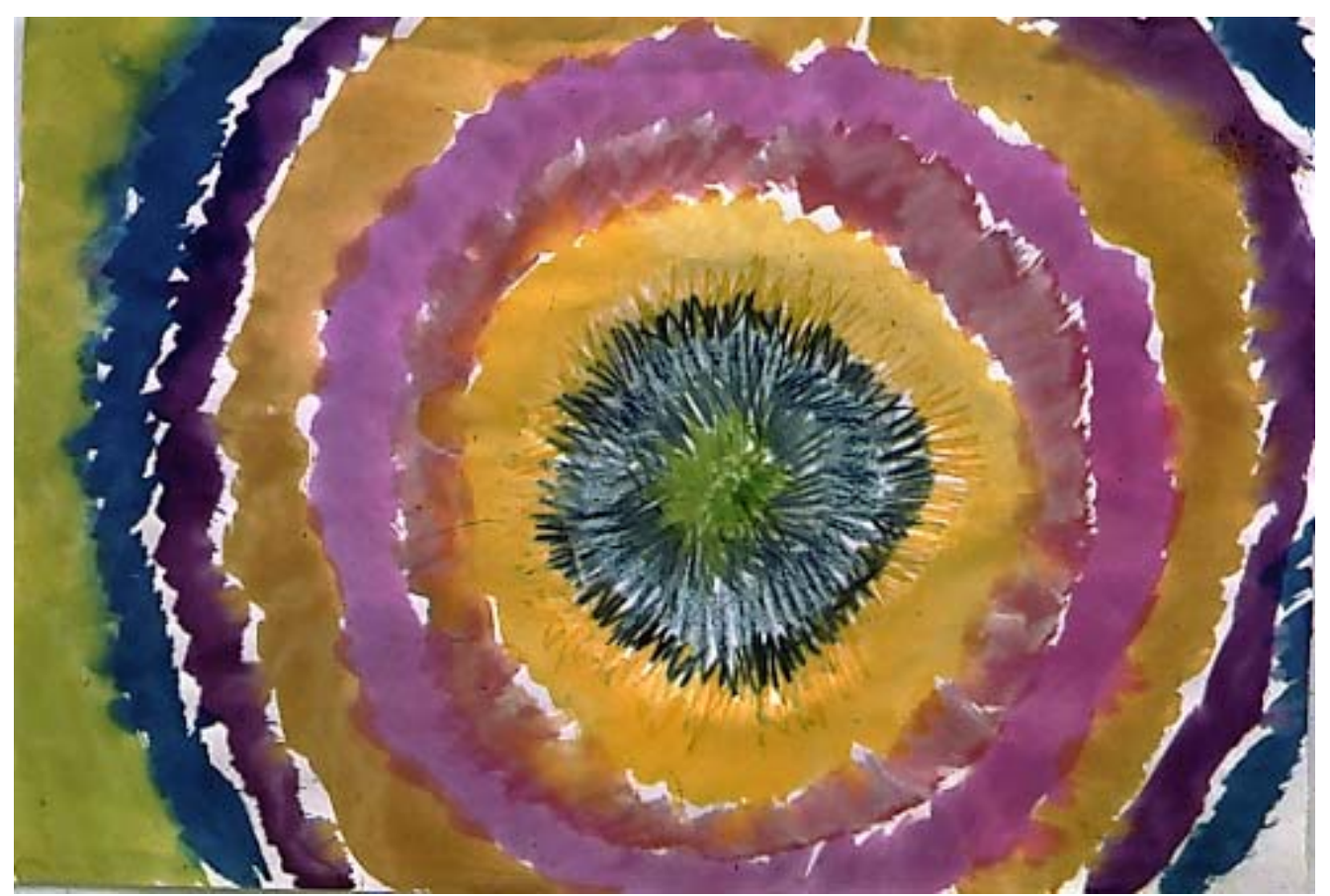

Primeira tentativa de desenho/pintura considerada inadequada pela aluna. 


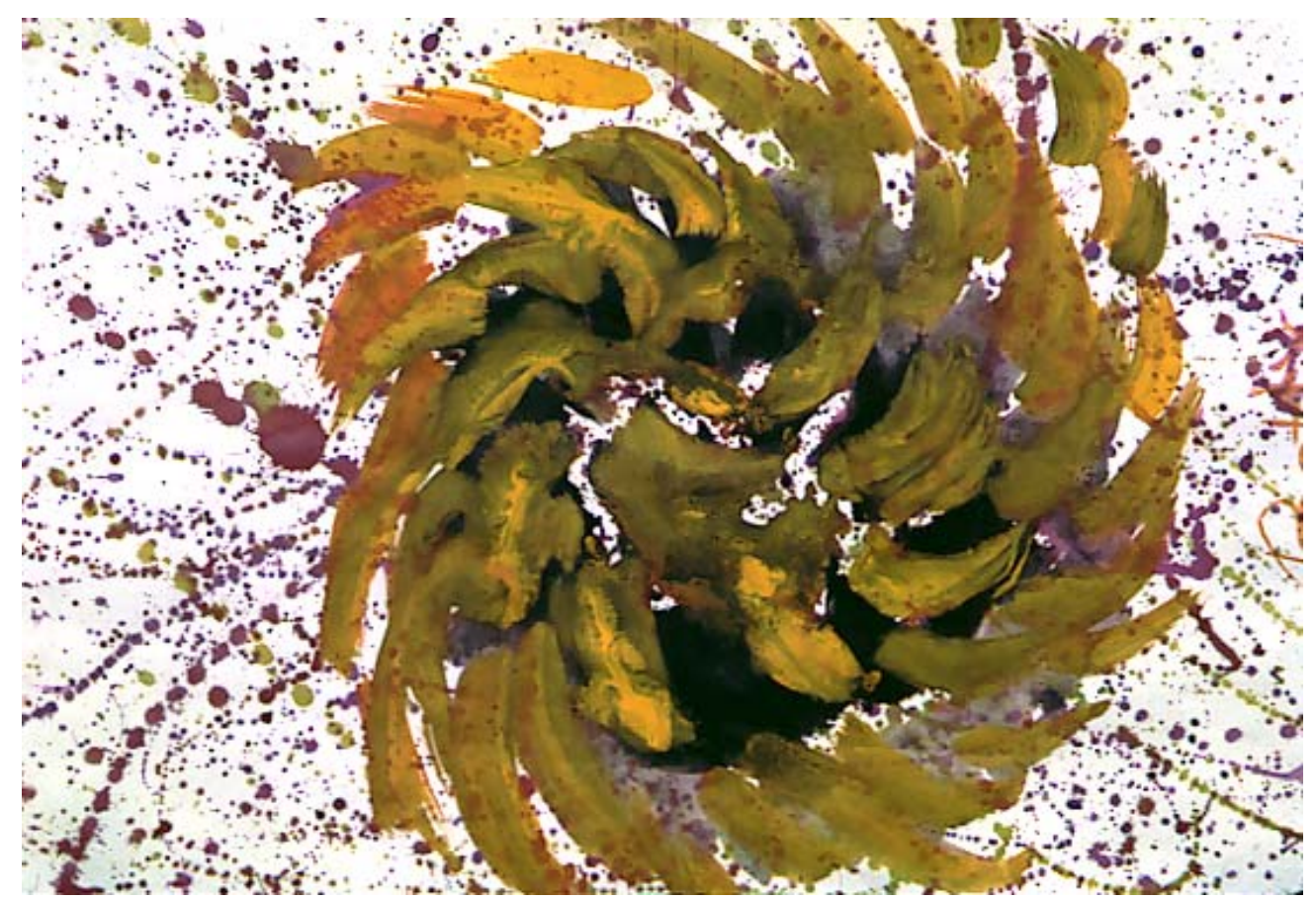

Segunda tentativa, considerada inadequada pela aluna por parecer uma explosão e não uma expansão

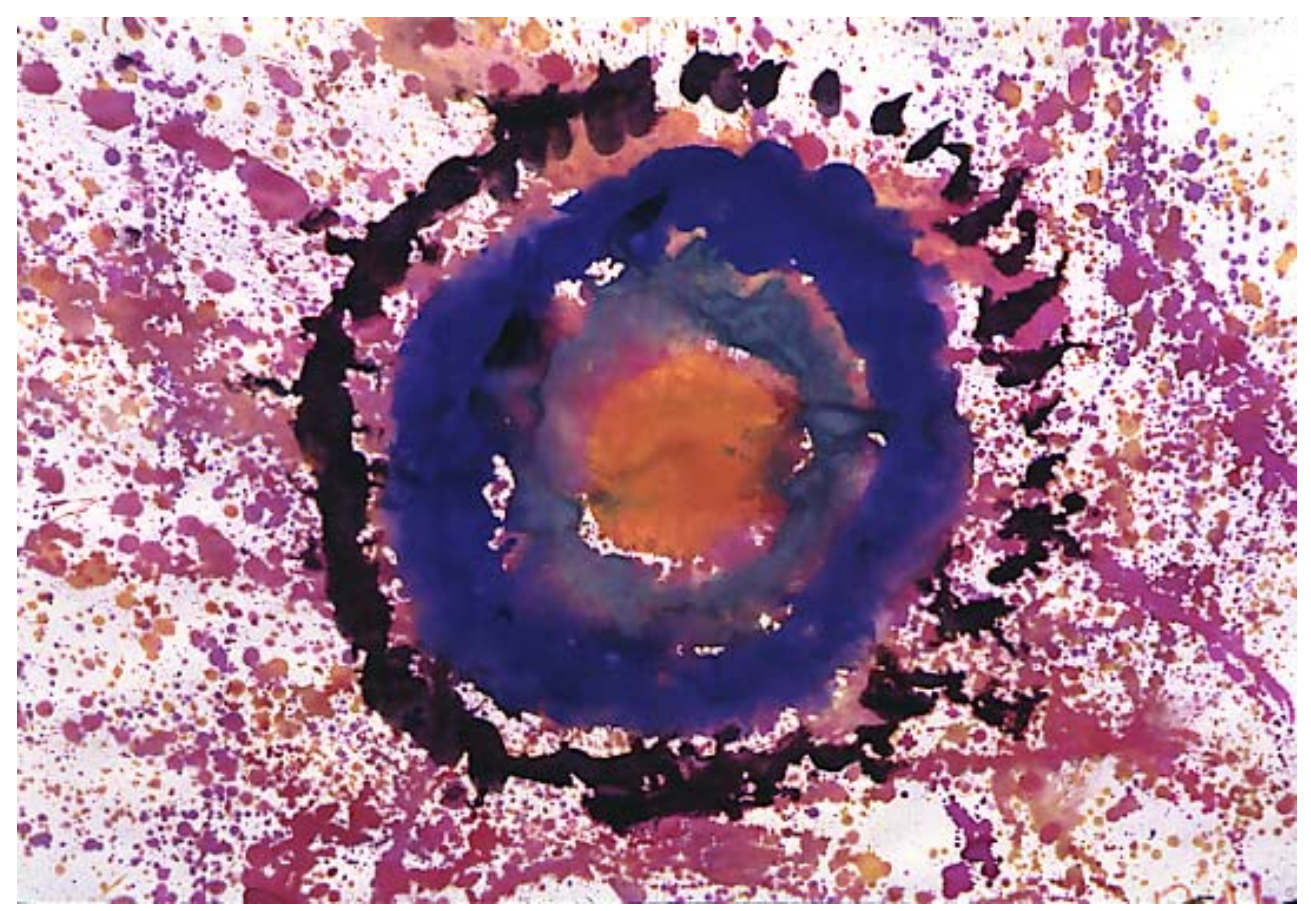

Terceira tentativa, desenho/pintura considerado adequado pela aluna e elogiado pelos colegas. 


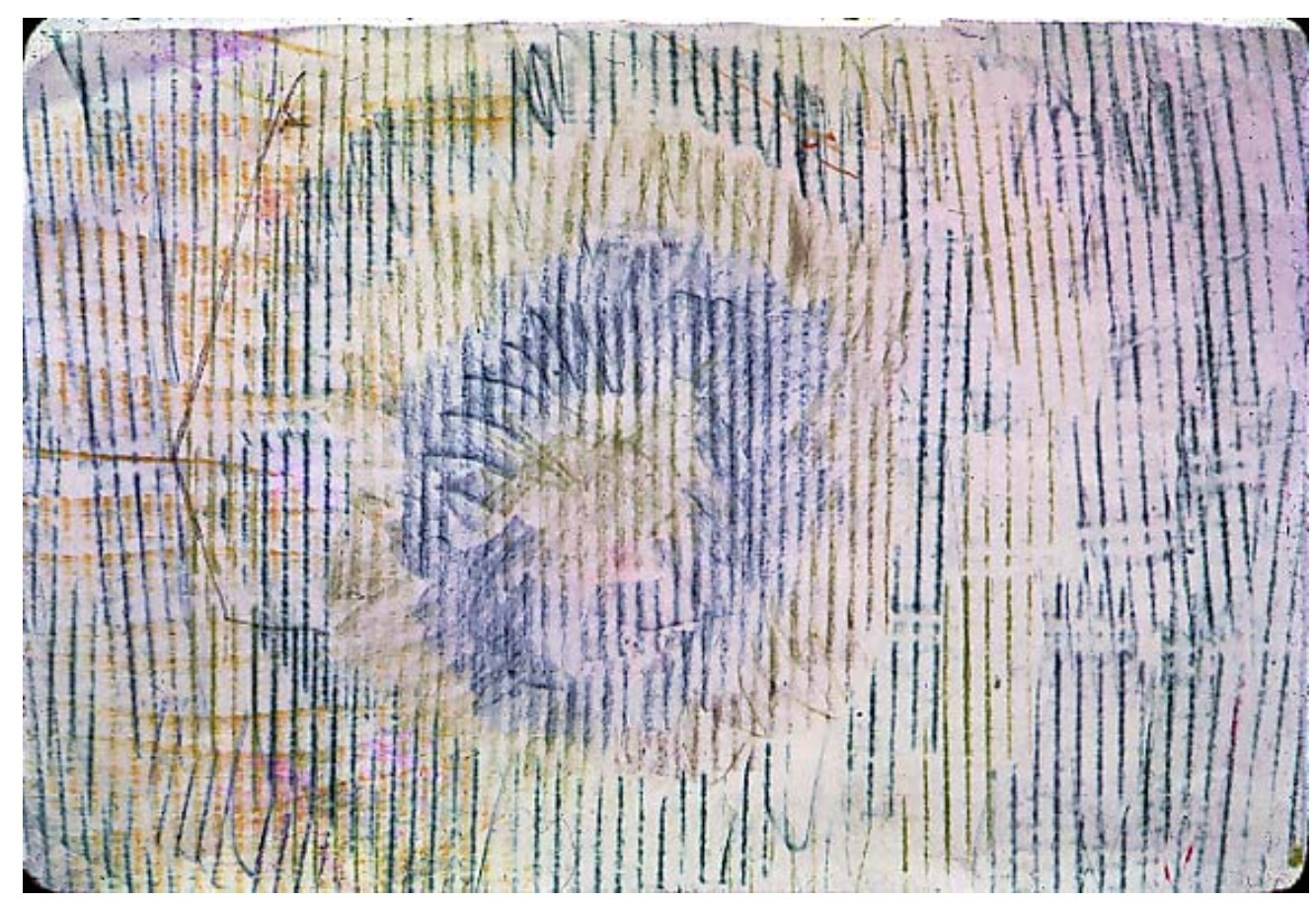

Continuando a experiência, a aluna considerou este desenho o mais adequado para representar a ideia de expansão.

Fotos produzidas por alunos e alunas da EASP 


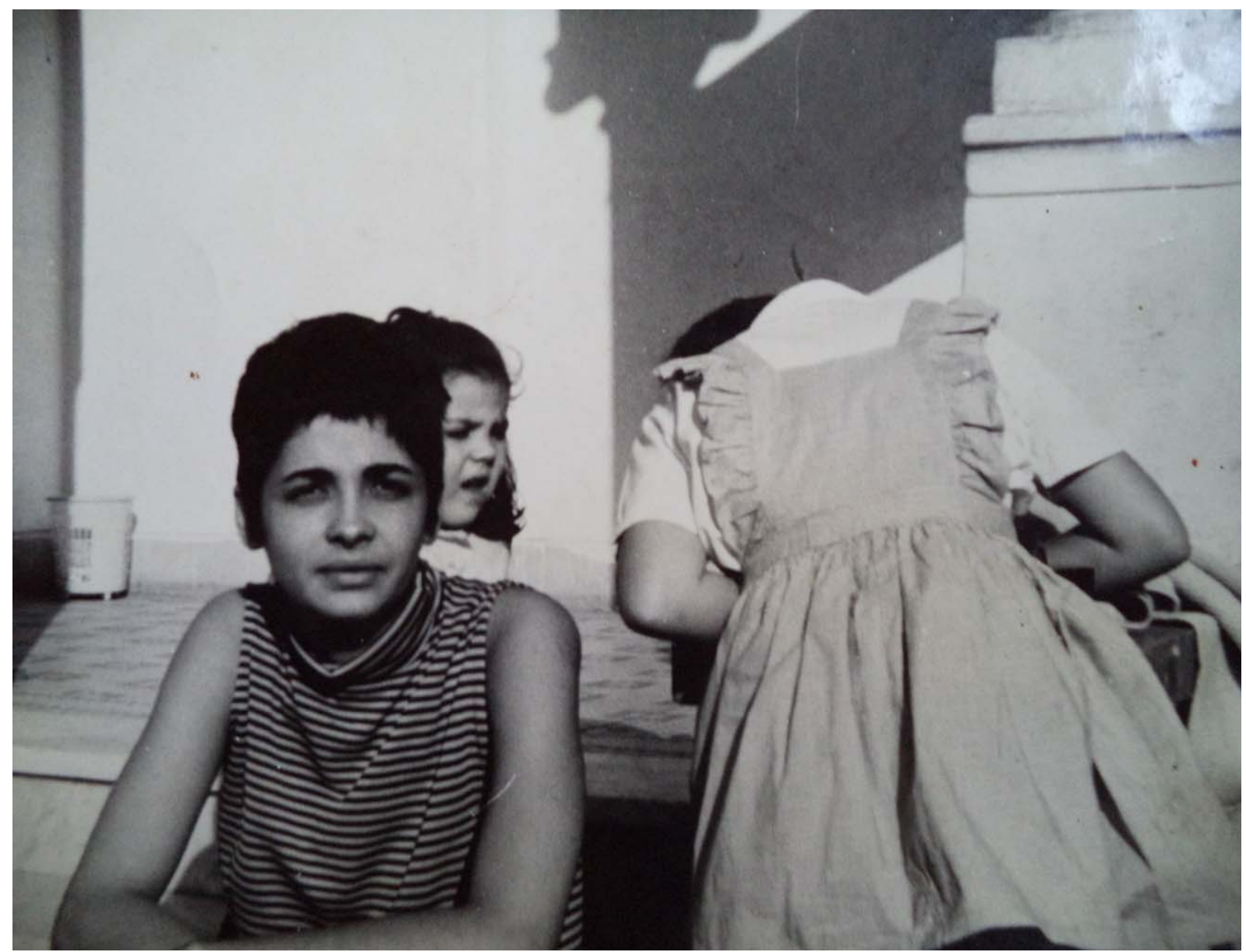

Professora Madalena Freire. 


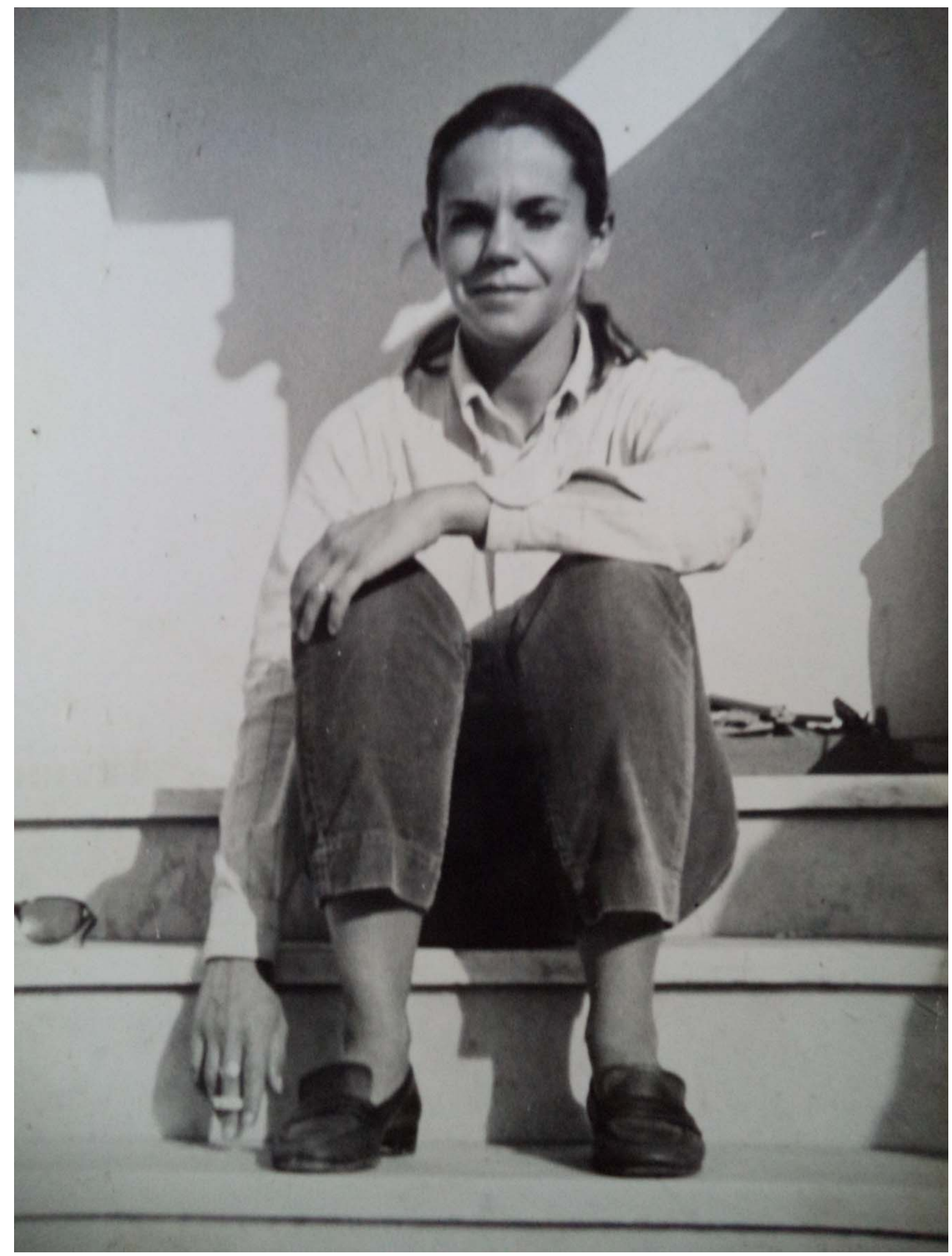

Professora Regina Gomes. 


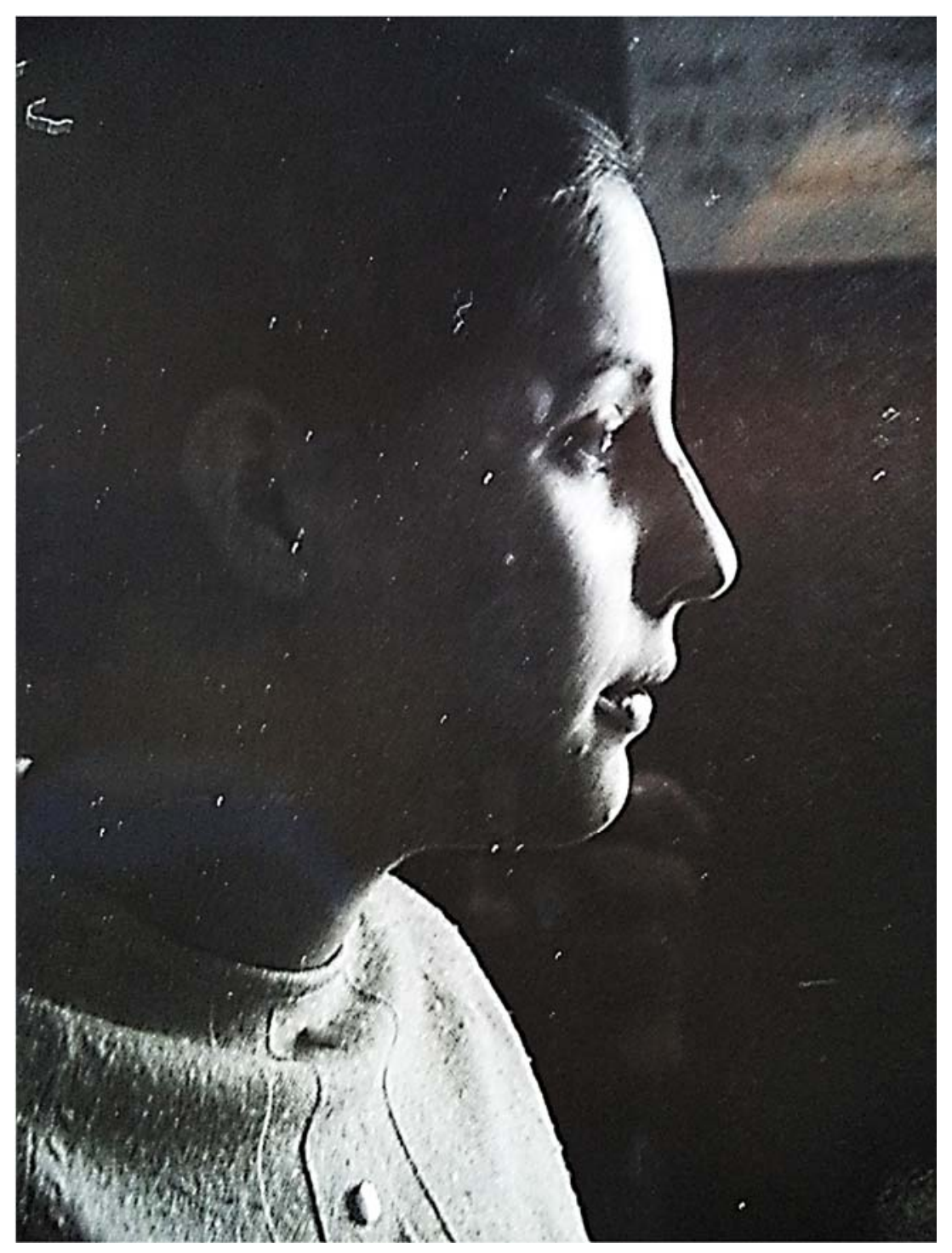

Estagiária Regina Machado. 


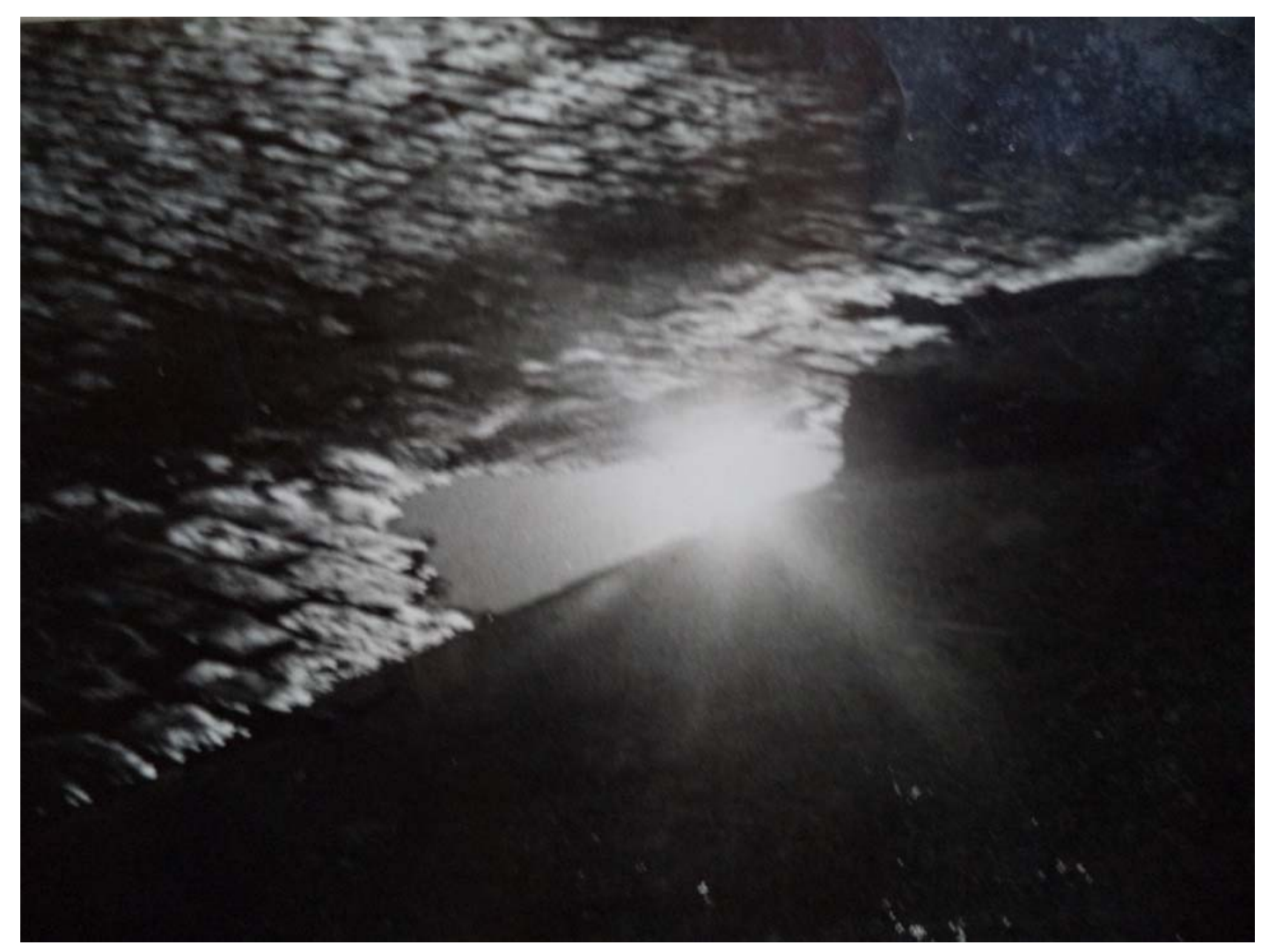

\section{Referências}

BARBOSA, Ana Mae. Teoria e Prática da Educação Artística. Cultrix, 1975.

BARBOSA, Ana Mae. Arte-Educação: conflitos e acertos. São Paulo: Max Limonad, 1984.

BARBOSA, Ana Mae. História da Arte/Educação: a experiência de Brasília. São Paulo: Max Limonad, 1986.

BARBOSA, Ana Mae. A imagem no ensino da arte: anos 80 e novos tempos. São Paulo: Perspectiva, 2009.

LIMA, Sidiney Peterson F. de. Escolinha de Arte de São Paulo: instantes de uma história. Dissertação de mestrado. São Paulo: IS-UNES, 2014. 


\section{Ana Mae Barbosa}

Possui graduação em Direito pela Universidade Federal de Pernambuco (1960), mestrado em Art Education pela Southern Connecticut State College (1974) e doutorado em Humanistic Education pela Boston University (1978). Atualmente é Professora Titular aposentada da Universidade de São Paulo e professora da Universidade Anhembi Morumbi. Foi presidente da International Society for Education through Art (InSEA), da Associação Nacional de Pesquisadores em Artes Plásticas (ANPAP) e diretora do Museu de Arte Contemporânea da USP. Tem livros e artigos publicados em diversos países. Tem experiência na área de Artes, com ênfase em Arte/Educação, atuando principalmente nos seguintes temas: Ensino da Arte e contextos metodológicos, História do Ensino da Arte e do Desenho, Ensino do Design, Administração de Arte, Multiculturalidade, Estudos de Museus de Arte e Estudos Visuais.

E-mail: anamaebarbosa@gmail.com

Currículo: http://lattes.cnpq.br/1650414096296319

\section{Sidiney Peterson Ferreira de Lima}

Possui graduação em Pedagogia pela Universidade Federal Rural de Pernambuco (UFRPE, 2010), mestrado em Artes pela Universidade Estadual Paulista (UNESP, 2014). Experiência na área de Educação, Educação em Museus e Mediação Cultural. Tem desenvolvido pesquisas com foco na história do ensino de artes e na formação de arte/educadores no Brasil.

E-mail: sidney.peterson@gmail.com

Currículo: http://lattes.cnpq.br/7897838185394600 